\title{
Implementation Science and Urban Health Research
}

\section{Sebastian Bonner}

Much recent attention in medicine and public health has been focused on promoting translation of bench science (i.e., drug discovery) to bedside utility. This, in essence, is applied clinical science. Minor mention has been made of the larger problem, namely, the failure to achieve broad adoption of these "translation" successes. For example, an efficacious and effective hepatitis B vaccine has been licensed for over two decades, yet uptake among the highest risk group, injection drug users, has remained low. ${ }^{1,2}$ Annual rates of influenza immunization consistently fall far short of public health goals. ${ }^{3}$ The rates for appropriate use for asthma controller medications remain disturbingly low. ${ }^{4,5}$ Many other examples of failure to translate medical discovery into clinical implementation exist. A palms-up shrug with eye rolling is neither efficacious nor effective in addressing this public health issue. A more productive response is to investigate what it takes for findings from good science to reach the public.

Implementation science is the study of methods to promote the transfer of research findings into routine healthcare policy and practice. This is an evolving, interdisciplinary field, one of several efforts to bridge the science-to-practice gap. An extensive process of translation from bench research precedes final implementation. Two translation roadblocks in the path from science to practice were identified in the United States by the Institute of Medicine's Clinical Research Roundtable as T1 and $\mathrm{T} 2 .^{6,7} \mathrm{~T} 1$ is the translation of new understandings of disease mechanisms into new methods of diagnosis, therapy and prevention, and their first testing in humans. $\mathrm{T} 2$ is the translation of results from clinical studies into everyday clinical practice. Clinical guidelines are one mechanism for translating clinical results into practice, but they are often insufficient to change practice habits. ${ }^{8,9}$ For example, the National Heart, Lung and Blood Institute first published the Guidelines for the Diagnosis and Management of Asthma in $1991 .{ }^{10}$ Guidelines were updated in $1997^{11}$ and $2007,{ }^{12}$ but they have been plagued by evidence of problems in uptake. $^{13-17}$

Recently, Westfall and colleagues proposed that there are two stages after T1. ${ }^{18}$ In their view, T2 is translation to patients through guidelines, meta-analyses, and systematic review, and T3 is translation to practice through dissemination and implementation research. Another elaboration of T2 comes from the Canadian Institutes of Health Research. ${ }^{19}$ They describe knowledge translation as a dynamic and iterative process that includes synthesis, dissemination, exchange, and ethnically sound application of knowledge to improve the health of Canadians, provide more

\footnotetext{
Bonner is with the New York Academy of Medicine, New York, NY, USA.

Correspondence: Sebastian Bonner, New York Academy of Medicine, New York, NY 10029, USA. (E-mail: sbonner@nyam.org)
} 
effective health services and products, and strengthen the health care system. Knowledge translation can occur at the end of a research project through a plan to disseminate findings to potential users, or it can be integrated into the research by involving knowledge users into the research process.

There is a truism in science that two standards of evidence need to be reached before results are deemed ready for implementation into routine practice. Evidence of efficacy comes when results establish causality under optimal conditions, and evidence of effectiveness is seen when results hold true under generalizable realworld conditions. Research that focuses squarely on implementation is needed because of contextual realities that dilute the public health impact of interventions that reach these standards of evidence. Russell Glasgow of Kaiser Permanente's Center for Dissemination and Implementation Research has described a scenario that begins with a breakthrough medical advance-the discovery of a specific genetic basis for a highly prevalent disorder-and development of a highly efficacious preventive treatment. ${ }^{20,21}$ With realistic to optimistic estimates of the impact of a nationwide dissemination effort to promote the use of this drug, his scenario illustrates how a treatment with a large effect size $(50 \%$ reduction compared to a double-blind placebo control condition) that affects $50 \%$ of the population ends up having $0.1 \%$ to $3 \%$ population-wide impact. The $50 \%$ efficacy achieved in the RCT is diluted by the rate of adoption at the clinic level and the individual provider level and the rate of acceptance by patients, their adherence rate, and continued long-term effects. Glasgow has categorized the steps involved in translating a basic science breakthrough into real-world practice into the RE-AIM framework, around which much implementation research is presently conducted. ${ }^{22}$ RE-AIM stands for Reach (into the target population), Efficacy (or effectiveness), Adoption (by target settings or institutions), Implementation (consistency of delivery) and Maintenance (of intervention effects in individuals and populations over time), and the framework is supported by a number of useful web-based tools (www.re-aim.org).

As implementation science develops, what becomes clear is how strong a role it may play in urban health research. ${ }^{23,24}$ As with any emerging field, there are inconsistencies in the use of terms used by researchers in implementation science. Rabin and colleagues have compiled a glossary of terminology used in frequently cited articles and funding announcements. ${ }^{25}$ Their glossary is organized by foundational concepts, types of research, models, moderators and mediators, and measurement and evaluation. The relevance to urban health research is evident throughout their excellent overview. One of the foundational concepts is that health promotion efforts be built on evidence-based interventions (EBIs). Compilations of EBIs include the Centers for Disease Control and Prevention's Guide to Community Preventive Services (www.thecommunityguide.org), the Agency for Healthcare Research and Quality's Guide to Clinical Preventive Services (http://ftp.ahrq.gov/ clinic/pocketgd07/pocketgd.htm), and Cochrane Reviews. ${ }^{26,27}$ HIV interventions developed in response to the Trans-NIH Strategic Plan for HIV-related Research can be found at http://www.effectiveinterventions.org. One way that these interventions are being disseminated is through the CDC Diffusion of Effective Behavioral Interventions (DEBI) project (http://www.effectiveinterventions.org/). A range of strategies is available once the EBIs have been identified depending on the structures of the interventions and the aim of the research, from diffusion (the least focused and most cursory) to dissemination (active approaches for spreading EBIs to target audiences via determined channels using planned strategies) to implementation 
(putting EBIs to use within a public setting). Typically addressed in implementation research is the degree to which the implementation effort maintains fidelity to the EBI or requires reinvention or adaptation to suit local conditions. Implementation studies also address factors that affect adoption of the EBI such as relative advantage, characteristics of the individual adopters, organizational and community factors, and structural and community features. Outcomes may be measured at the individual and organizational or population level and may include impacts on quality of life, adverse consequences, and economic evaluation. These outcomes most often call for mixed methods.

It is encouraging to see that NIH, CDC, and other funding agencies have issued program announcements that support this important public health need. As research progresses, so too will appropriate and successful adoption of evidence-based interventions in community and clinic settings.

\section{REFERENCES}

1. Ompad DC, Galea S, Wu Y, et al. Acceptance and completion of hepatitis B vaccination among drug users in New York City. Commun Dis Public Health. 2004;7(4):294-300.

2. Amesty S, Ompad DC, Galea S, et al. Prevalence and correlates of previous hepatitis B vaccination and infection among young drug-users in New York City. J Community Health. 2008;33(3):139-148.

3. CDC. Vaccination trends. http://www.cdc.gov/flu/professionals/vaccination/pdf/vaccinetrend. pdf. Accessed September 4, 2008.

4. De Smet BD, Erickson SR, Kirking DM. Self-reported adherence in patients with asthma. Ann Pharmacother. 2006;40(3):414-420.

5. Bonner S, Matte T, Rubin M, Fagan JK, Ahern J, Evans D. Oral beta(2)-agonist use by preschool children with asthma in East and Central Harlem, New York. J Asthma. 2006;43(1):31-35.

6. Woolf SH. The meaning of translational research and why it matters. JAMA. 2008;299 (2):211-213.

7. Fiscella K, Bennett NM, Szilagyi PG. Nomenclature in translational research. JAMA. 2008;299(18):2148-2149.

8. Mittman BS, Tonesk X, Jacobson PD. Implementing clinical practice guidelines: social influence strategies and practitioner behavior change. QRB Qual Rev Bull. 1992;18 (12):413-422.

9. Fang E, Mittman BS, Weingarten S. Use of clinical practice guidelines in managed care physician groups. Arch Fam Med. 1996;5(9):528-531.

10. National Asthma Education and Prevention Program. Guidelines for the Diagnosis and Management of Asthma. Expert Panel Report 1. 1991. Bethesda, MD, NIH, National Heart, Lung, and Blood Institute. Pub. 91-4051.

11. National Asthma Education and Prevention Program. Guidelines for the Diagnosis and Management of Asthma. Expert Panel Report 2. 1997. Bethesda, MD, NIH, National Heart, Lung, and Blood Institute. Pub. 97-4051.

12. National Asthma Education and Prevention Program. Guidelines for the Diagnosis and Management of Asthma. Expert Panel Report 3. 2007. Bethesda, MD, NIH, National Heart, Lung and Blood Institute. Pub. 08-4051.

13. Scarfone RJ, Zorc JJ, Capraro GA. Patient self-management of acute asthma: adherence to national guidelines a decade later. Pediatrics. 2001;108(6):1332-1338.

14. Reeves MJ, Bohm SR, Korzeniewski SJ, Brown MD. Asthma care and management before an emergency department visit in children in western Michigan: how well does care adhere to guidelines? Pediatrics. 2006;117(4 Pt 2):S118-S126. 
15. Warman KL, Silver EJ, McCourt MP, Stein RE. How does home management of asthma exacerbations by parents of inner-city children differ from NHLBI guideline recommendations? Pediatrics. 1999;103(2):422-427.

16. Wilson SE, Leonard A, Moomaw C, Schneeweiss S, Eckman MH. Underuse of controller medications among children with persistent asthma in the Ohio medicaid population: evolving differences with new medications. Ambul Pediatr. 2005;5(2):83-89.

17. Marshall W. The paper by Wilson et al raises several important issues on the clinicalresearch interface. Ambul Pediatr. 2005;5(5):311-312.

18. Westfall JM, Mold J, Fagnan L. Practice-based research-"Blue Highways" on the NIH roadmap. JAMA. 2007;297(4):403-406.

19. Lomas J. Using 'linkage and exchange' to move research into policy at a Canadian foundation. Health Aff (Millwood). 2000;19(3):236-240.

20. Glasgow RE. What types of evidence are most needed to advance behavioral medicine? Ann Behav Med. 2008;35(1):19-25.

21. Dzewaltowski DA, Estabrooks PA, Klesges LM, Bull S, Glasgow RE. Behavior change intervention research in community settings: how generalizable are the results? Health Promot Int. 2004;19(2):235-245.

22. Glasgow RE, Vogt TM, Boles SM. Evaluating the public health impact of health promotion interventions: the RE-AIM framework. Am J Public Health. 1999;89 (9):1322-1327.

23. Bernstein SL, Bernstein E, Boudreaux ED, et al. Public health considerations in knowledge translation in the emergency department. Acad Emerg Med. 2007;14(11):1036-1041.

24. Madon T, Hofman KJ, Kupfer L, Glass RI. Public health. Implementation science. Science. 2007;318(5857):1728-1729.

25. Rabin BA, Brownson RC, Haire-Joshu D, Kreuter MW, Weaver NL. A glossary for dissemination and implementation research in health. J Public Health Manag Pract. 2008;14(2):117-123.

26. Waters E, Armstrong R. Knowledge synthesis, translation and exchange in public health and health promotion: the role of a Cochrane Review Group. Promot Educ. 2007;14 (1):34-35.

27. Waters E, Doyle J, Jackson N, Howes F, Brunton G, Oakley A. Evaluating the effectiveness of public health interventions: the role and activities of the Cochrane Collaboration. J Epidemiol Community Health. 2006;60(4):285-289. 